\title{
ANALISIS BALANCED SCORECARD PADA PABRIK GARMEN (KASUS:PT. HANDSUMTEX)“
}

\author{
William \\ Program Studi Magister Manajemen Universitas Tarumanagara \\ wildow91@gmail.com
}

\begin{abstract}
A marketing strategy is a way of introducing a company in a form or service with a competitive advantage over an existing competitor. Marketing strategy is often used as a reference to prepare the company plan, which from the reference can be poured into careful planning to be used as an idea of the company to run business activities. Garment industry is a fast growing industry due to the technology and demand from consumers in accordance with the era of globalization. This research has a purpose to get an idea about marketing strategy to improve competitiveness, and to know how effective execution of marketing strategy that have been done. This research was conducted at PT. Handsumtex, from internal and external factors will be made Balanced Scorecard analysis. Data collection techniques with documentation, interviews and observation, descriptive research. The results of the effectiveness analysis of marketing strategy shows an increase in total sales from year to year and serve as a reference to the effectiveness of marketing strategies in competition between garment factories.
\end{abstract}

Keywords : Marketing Strategy, Garment Factory, Competitiveness

\section{PENDAHULUAN}

Didalam persaingan dunia garment yang semakin ketat, apabila posisi atau strategi dari suatu perusahaan garment yang dapat bertahan dalam kondisi yang stabil merupakan suatu cerminan kesuksesan perusahaan garment tersebut. Masing-masing perusahaan garment berkompetisi untuk menciptakan inovasi yang baru, mengeluarkan suatu design yang berbeda, bergaya unik (fashionable), berkualitas dan harga yang setara dengan kualitas yang ditawarkan.

PT. Handsumtex adalah perusahaan yang bergerak di bidang industri garment. Pada saat itu, banyak sekali para buyer garment berdatangan untuk mencari partner untuk bekerja sama. PT. Handsumtex dapat memenuhi permintaan pelanggan yang sangat beraneka ragam dalam sisi design maupun kekompetitifan dalam harga dan juga dapat menguasai pasar Celana yoga dengan baik dan didukung adanya added value. Para analis riset pasar telah berusaha untuk menjelaskan tren di Amerika bagian Utara karena disana telah menjadi budaya bukan hanya dipakai selama gym saja, bahkan dipakai selama kegiatan sehari-hari (Brundage, 2012).

Untuk dapat memberikan input agar dapat bertahan dan menghadapi kompetisi persaingan yang semakin kuat, maka penulis menyusun tesis dengan judul "ANALISIS BALANCED SCORECARD PADA PABRIK GARMENT (KASUS:PT. HANDSUMTEX)“

\section{RUMUSAN MASALAH}

Permasalahan penelitian yang akan dijawab adalah bagaimana strategi perusahaan dengan menerapakan analisis balanced scorecard?

\section{TUJUAN PENELITIAN}

Tujuan dari penelitian ini, berdasarkan rumusan masalah yang telah dikemukakan sebelumnya maka penelitian ini memiliki tujuan menemukan strategi strategi perusahaan dengan menerapakan analisis balanced scorecard. 


\section{MANFAAT PENELITIAN}

Manfaat Penelitian, hasil penelitian yang dilakukan oleh peneliti diharapkan dapat memberikan kontribusi yang baik kepada berbagai pihak yakni:

1. Bagi Perusahaan

Penelitian ini diharapkan memberikan masukan kepada PT. Handsumtex dalam mempertahankan posisi perusahaan dan meningkatkan kinerja usaha, baik dalam jangka pendek maupun jangka panjang

2. Bagi masyarakat umum

Penelitian ini diharapkan dapat menambah pengetahuan, dan juga bisa sebagai referensi untuk penelitian di masa depan.

3. Bagi penelitian selanjutnya

Sebagai acuan bagi para akademisi untuk dikembangkan lebih lanjut dalam penelitian yang lebih spesifik atau penelitian yang bekaitan dengan topik ini.

\section{LANDASAN TEORI}

\section{Visi dan Misi Perusahaan}

Visi bertindak sebagai sumber dari ide sebuah perusahaan, dimana ide tersebut dipakai untuk menggambarkan bagaimana perusahaan harus kelihatan seperti apa di masa yang akan datang, mengformulasikan ideologi yang ada, dan memberikan pedoman kepada perusahaan bagaimana pekembangannya di masa depan (Stefan, 2010:2)

Menurut Stefan Sabrautzki (2010:3), misi adalah bertindak sebagai tujuan inti utama dari suatu perusahaan yang dimana menjadi suatu ciri khas yang membedakan perusahaan kita dari perusahaan-perusahaan lain yang ada. Tujuan utama ini juga sebisa mungkin tidak bisa berubah dan bertahan selama mungkin.

\section{Fashion Industry}

Salah satu kebutuhan pokok manusia yang harus terpenuhi adalah sandang/busana, karena mempunyai fungsi dasar untuk melindungi tubuh dan mencegah hal-hal yang menyimpang dari unsur-unsur kesusilaan. Disamping itu, busana memiliki fungsi untuk mengekspresikan diri dan menunjukkan status sosial yang ada pada seseorang. Namun yang perlu diketahui adalah perkembangan mode design pada busana berlangsung sangat cepat di Indonesia. Ini disebabkan dampak globalisasi, karena efek globalisasi itu sendiri menghadirkan sebuah peluang yang sekaligus memberikan resiko dan tantangan (Rahman, 2013:9).

\section{Lingkungan Eksternal}

Menurut Pearce dan Robinson (2015:88), lingkungan eksternal adalah sejumlah faktor-faktor diluar kendali perusahaan yang mempengaruhi arah dan tindakan perusahaan, yang dimana semuanya itu akan berpengaruh ke struktur organisasi dan proses internal dari perusahaan itu sendiri.

\section{Lingkungan Industri}

Lingkungan industri merupakan sekumpulan faktor-faktor yang mempengaruhi perusahaan dalam menentukan aksi dan tanggapan kompetitifnya. Menurut Porter (2008:3) mengajukan model lima kekuatan (five forces model) sebagai alat untuk menganalisis lingkungan persaingan industri. Lima kekuatan itu adalah ancaman masuknya pendatang baru, daya tawar pemasok, daya tawar pembeli, ancaman barang pengganti, ancaman pesaing perusahaan yang sama. 


\section{Analisis Faktor Internal}

Lingkungan internal adalah segala macam hal yang berhubungan dalam lingkungan organisasi atau perusahaan dan memiliki pengaruh langsung pada perusahaan/organisasi tersebut. Menurut Griffin (2008:36), organisasi/perusahaan memiliki lingkungan internal dimana terdiri dari pemilik, dewan direksi, karyawan dan lingkungan kerja fisik dari perusahaan itu

\section{Balanced Scorecard}

Menurut Asefeso (2013:8), Balanced Scorecard adalah suatu sistem manajemen yang memungkinkan organisasi Anda untuk menetapkan, melacak dan mencapai strategi dari tujuan bisnis utamanya. Dimana, ketika strategi-strategi bisnis telah dikembangkan, maka akan dapat diterapkan dan dilacak melalui empat perspektif yang bisa digunakan oleh eksekutif dan manager untuk merencanakan, mengimplementasikan dan mencapai strategi yang ada di bisnis mereka.

\section{Peta Strategi}

Strategy Map adalah sebuah diagram yang menunjukan visi, misi, strategi organisasi diimplementasikan dalam aktivitas sehari-hari pada setiap unit bisnis dengan menggunakan KPI (Key Performance Indicator) (Niven, 2010:92).. Dengan menggunakan strategy map bisa di dilihat dengan jelas keterkaitan antar visi, misi organisasi dengan KPI Strategy Map dibuat dengan menghubungkan strategi objektif organisasi secara eksplisit dengan masingmasing KPI yang dikelompokkan dalam ke empat perspektif balance scorecard (financial, customer, internal business process dan Learning \& growth).

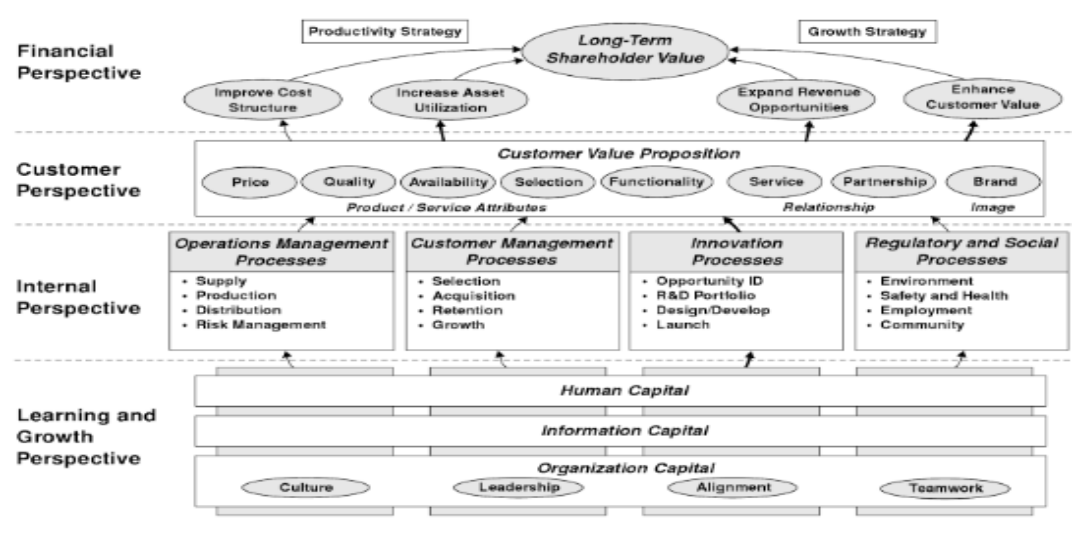

Gambar Empat Perspektif Balanced Scorecard

(Kaplan, 2015:14)

\section{METODE PENELITIAN}

\section{Metode dan Tipe / Jenis Penelitian}

Pendekatan penelitian yang dilakukan oleh peneliti adalah penelitian kualitatif didasarkan informasi yang diberikan oleh manajemen PT. Handsumtex dan narasumber lain. Kegiatan pengumpulan data melalui wawancara ini dilakukan secara langsung dengan Manajer Produksi selama 3 bulan mulai tanggal 1 Desember 2017 sampai dengan 28 Febuari 2018 dengan menghasilkan 12 pertanyaan beserta hasil jawabannya diolah dan dianalisa dengan dasar teori yang ada.

Jenis penelitian yang digunakan adalah penelitian deskriptif di mana suatu metode penelitian yang memiliki tujuan untuk mendeskripsikan atau menggambarkan kejadian yang ada yang terjadi saat ini maupun saat lampau. 
Dengan demikian dalam penelitian ini mengemukakan strategi yang tepat pada PT. Handsumtex dengan menggunakan analisis Balanced Scorecard.

\section{Teknik Analisis Data}

Teknik analisis data yang digunakan adalah menggunakan analisis lingkungan internal dan eksternal, analisis visi dan misi perusahaan, analisis Balanced Scorecard, Strategy Map.

\section{ANALISIS HASIL DAN PEMBAHASAN}

Dari hasil analisa dari lingkungan internal dan eksternal dapat disimpulkan bahwa untuk analisa faktor eksternal dan internal dari PT. Handsumtex adalah sebagai berikut:

\begin{tabular}{|c|c|c|}
\hline EKSTERNAL/INTERNAL & Kekuatan (STRENGTH) & Kelemahan (WEAKNESS) \\
\hline & $\begin{array}{l}\text { S1. high quality product } \\
\text { S2. Sumber Daya Manusia yang } \\
\text { berpengalaman } \\
\text { S3. dapat raw material lbh murah }\end{array}$ & $\begin{array}{l}\text { W1. Banyaknya karyawan yang berusia } 40 \text { tahun } \\
\text { ke atas } \\
\text { W2. Bisnis berfokus pada } 1 \text { produsen yaitu } \\
\text { Lululemon }\end{array}$ \\
\hline Peluang (OPPORTUNITY) & Strategi S-O & Strategi W-O \\
\hline $\begin{array}{l}\text { O1. Kawasan PT. Handsumtex } \\
\text { adalah termasuk kawasan bebas } \\
\text { pajak/ Kawasan Industri } \\
\text { Berikat } \\
\text { O2. Client yang sudah loyal } \\
\text { O3. Kemajuan telnologi pada } \\
\text { bidang garment } \\
\text { O4. Berubahnya gaya hidup di } \\
\text { beberapa Negara menjadi } \\
\text { banyak berolahraga untuk } \\
\text { hidup sehat }\end{array}$ & $\begin{array}{l}\text { 1. Mempertahankan dengan follow up } \\
\text { customer dari luar negeri [S1_S3 } 31,02] \\
\text { 2. Tetap mengikuti perkembangan telnologi } \\
\text { tekstil dengan aktif turut serta dalam pameran } \\
\text { garment [S2, } \mathrm{O} 3] \\
\text { 3. Dikarenakan keuntungan bahan baku yang } \\
\text { murah dan juga keuntungan yang terletak di } \\
\text { kawasan berikat sehingga bisa memberikan } \\
\text { harga yang kompetitif maka kesempatan } \\
\text { untuk menarik pelanggan baru [S3,O1,O4] }\end{array}$ & $\begin{array}{l}\text { 1. Mendidik karyawan yang baru untuk } \\
\text { menggantikan posisi karyawan yang sudah tidak } \\
\text { produktif lagi dan juga merekrut dari pihak } \\
\text { ekstemal untuk staf tenaga ahli [W1, } 3 \text { ] } \\
\text { 2. Menjaga pelayanan dan kualitas hasil produksi, } \\
\text { agar PT. Lululemon tetap berlangganan [W2 Q2] } \\
\text { 3. Karena adanya kemajuan telnologi seharusnya } \\
\text { memicu perusahaan untuk mengembangkan } \\
\text { telnologi untuk bisa menarik perhatian dari } \\
\text { customer baru [W2.Q3] } \\
\text { 4. Dengan adanya peluang gaya hidup di beberapa } \\
\text { Negara yang gemar hidup sehat,maka permintaan } \\
\text { akan perlengkapan olahraga semakin meningkat, } \\
\text { sekcaligus akan meningkatkan produksi di } \\
\text { Perusahaan [W2,04] }\end{array}$ \\
\hline Ancaman (THREAT) & Strategi S-T & Strategi W-T \\
\hline $\begin{array}{l}\text { T1. Adanya ancaman } \\
\text { kompetitor pada daerah yang } \\
\text { sama } \\
\text { T2. Adanya ancaman pesaing } \\
\text { baru dengan harga yang } \\
\text { kompetitif di daerah Jawa }\end{array}$ & $\begin{array}{l}\text { 1. Mempertahankan mutu produksi agar } \\
\text { kepercayaan customer tidak hilang sehingga } \\
\text { kehadiran kompetitor tidak terlalu berdampak } \\
\text { signifikan [S1,S2.T2] } \\
\text { 2. Memanfaatkan koneksi mendapat bahan } \\
\text { baku yang murah sehingga bisa bersaing } \\
\text { dengan kompetitor[S3,T1] }\end{array}$ & $\begin{array}{l}\text { 1. Adanya pemikiran untuk ekspansi ke daerah } \\
\text { Jawa untuk bisa berkompetitif harga dengan para } \\
\text { kompetitor [W2,T2] } \\
\text { 2. Hasil kualitas produksi harus tetap dijaga dan } \\
\text { ditingkatkan agar tidak mengecewakan Lululemon } \\
\text { [W2,T1] }\end{array}$ \\
\hline
\end{tabular}

\section{Analisis Visi dan Misi Perusahaan}

Visi dari PT. Handsumtex yang di terjemahkan ke dalam Bahasa Indonesia yaitu "Menjadi pabrik garmen kelas dunia dengan mempertahankan keungulan dalam keandalan, kualitas tinggi, nilai dan selalu terus membuat inovasi dan berkembang". Sedangkan misi perusahaan adalah : "Menghasilkan produk yang memenuhi syarat sesuai dengan spesifikasi, dengan pengiriman tepat waktu, Memberikan layanan terbaik kepada semua pelanggan kami, Meningkatkan sumber daya manusia, teknologi dan proses kedepannya.

Untuk menjadi pabrik garmen kelas dunia, PT Handsumtex perlu untuk mengetahui dan memperhatikan keinginan para pelanggan. Hal ini dilakukan agar PT. Handsumtex dapat menjawab semua tantangan yang diberikan oleh pelanggan, dikarenakan pada sisi garmen, sangat dibutuhkan inovasi dan juga teknologi yang mendukung. Maka ketika pelanggan memiliki order/design terbaru, PT. Handsumtex akan menjadi pilihan pertama bagi pelanggan.

\section{Tujuan Jangka Panjang dan Strategi Perusahaan}

Sasaran jangka panjang PT. Handsumtex adalah menjadi pabrik garmen kelas dunia dengan mempertahankan keungulan dalam keandalan, kualitas tinggi, nilai dan selalu terus 
membuat inovasi dan berkembang. Untuk mencapai sasaran/tujuan ini, maka PT. Handsumtex menerapkan beberapa strategi:

1. Fokus untuk customer Lululemon, karena secara garis besar Lululemon menguasai $60 \%$ kuota produksi yang ada pada PT. Handsumtex, dan juga menyiapkan lini produksi gedung tersendiri, sehingga Lululemon makin percaya dan terus memberikan design/order kepada PT. Handsumtex.

2. Melakukan pendekatan kepada agent untuk lebih bisa kooperatif dan juga mempromosikan lebih gencar lagi, lalu menerapkan sistem komisi yang menarik bagi agent.

3. Melakukan regenerasi mesin-mesin produksi yang sudah lama ke yang baru

4. Mengadakan acara kumpul dengan para agent untuk meningkatkan hubungan baik dengan para agent.

5. Mengadakan acara kumpul dengan pelanggan baru dan pelanggan lama untuk meningkatkan hubungan baik dengan para pelanggan.

\section{Faktor Kunci Keberhasilan}

Agar dapat meningkatkan daya saing, maka perusahaan perlu untuk mengetahui faktor kunci pendukung keberhasilan, Dari hasil wawancara yang dilakukan, terdapat faktor-faktor kunci keberhasilan yang diidentifikasi sebagai berikut:

1. Mempunyai kerjasama dengan produsen branded terkenal

2. Mempunyai supply bahan baku kain dengan kualitas dan harga yang baik

3. PT. Handsumtex memiliki Sumber Daya Manusia yang berpengalaman

4. PT. Handsumtex terletak pada Kawasan Berikat

\section{Pemetaan Strategi}

Dari analisa Visi dan Misi, faktor internal dan eksternal dan mempertimbangkan tujuang jangka panjang dan kunci faktor keberhasilan maka dirumuskan peta strategi sebagai berikut:

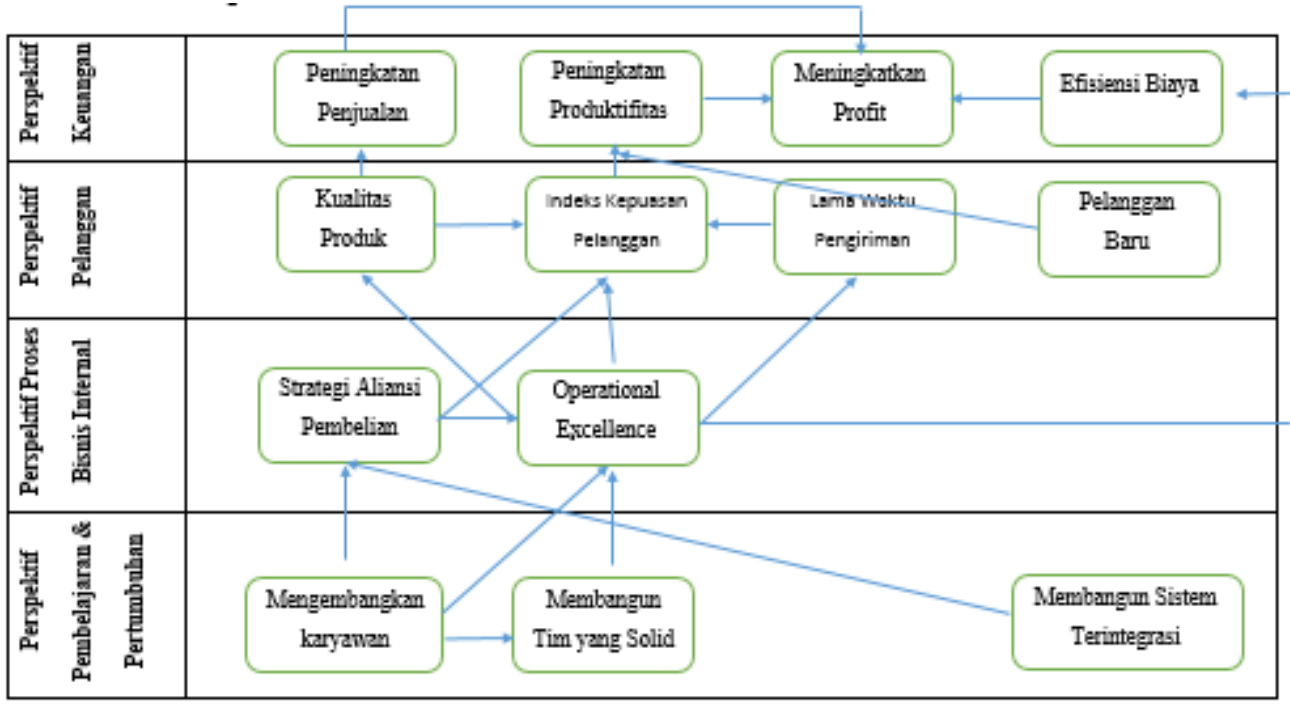




\section{Balanced Scorecard}

\begin{tabular}{|c|c|c|}
\hline Perspektif (Tujuan) & Ukuran & Strategi \\
\hline $\begin{array}{l}\text { Keuangan: } \\
\text { F1 - Meningkatkan } \\
\text { Profit } \\
\text { F2 - Pertumbuhan } \\
\text { Penjualan } \\
\text { F3 - Meningkatkan } \\
\text { Produktifitas } \\
\text { F4 - Efisiensi Biaya }\end{array}$ & $\begin{array}{l}\text { Net profit margin dan } R O I \\
\text { Persentase pertumbuhan } \\
\text { penjualan } \\
\text { Asset turnover } \\
\text { Perbandingan pendapatan dan } \\
\text { biaya } \\
\text { Penurunan biaya operasional }\end{array}$ & $\begin{array}{l}\text { F1 - F3: Berusaha menjadi market leader } \\
\text { F1: Meningkatkan penjualan dan menurunkan } \\
\text { biaya produksi } \\
\text { F2 - F3: Menjaga pelanggan yang ada, mencari } \\
\text { customer baru, terus berusaha mendekati } \\
\text { F4: Peningkatan produktivitas (menurunkan } \\
\text { produk tidak sesuai spesifikasi), mengurangi biaya } \\
\text { produksi \& operasi }\end{array}$ \\
\hline $\begin{array}{l}\text { Pelanggan: } \\
\text { C1 - Kualitas produk } \\
\text { C2 - Lama Waktu } \\
\text { Pengiriman } \\
\text { C3 - Index Kepuasan } \\
\text { Pelanggan } \\
\text { C4 - Pelanggan Baru }\end{array}$ & $\begin{array}{l}\text { Klaim produk dari pelanggan } \\
\text { Pengiriman produk tepat } \\
\text { waktu } \\
\text { Pengukuran indeks kepuasan } \\
\text { pelanggan (berdasarkan skor } \\
\text { audit dan komplain } \\
\text { pelanggan) } \\
\text { Persetujuaan dari pelanggan } \\
\text { baru }\end{array}$ & $\begin{array}{l}\text { C1 - C3: Memaksimalkan kualitas tinggi untuk } \\
\text { meningkatkan kepuasan pelanggan } \\
\text { C1: Membuat SOP untuk menjaga kualitas } \\
\text { yang tinggi } \\
\text { C2: Mengungkapkan umpan balik kepada } \\
\text { pelanggan, menyediakan sistem terintegrasi } \\
\text { untuk mempertahankan pembelian - produksi - } \\
\text { penjualan } \\
\text { C3: Memenuhi persyaratan standar dari } \\
\text { pelanggan } \\
\text { C4: Pendekatan pelanggan baru yang berada di } \\
\text { daerah market distribusi (Eropa,Canada, Amerika } \\
\text { Serikat), memancing dengan memberikan success } \\
\text { story dari pelanggan lama }\end{array}$ \\
\hline $\begin{array}{l}\text { Proses Bisnis Internal: } \\
\text { I1 - Strategi Supply } \\
\text { Chain } \\
\text { I2 - Operation Excellent }\end{array}$ & $\begin{array}{l}\text { Bekerja sama dengan } \\
\text { perusahaan bahan baku, dan } \\
\text { mempunyai anak perusahaan } \\
\text { pabrik bahan baku } \\
\text { Memaksimalkan kapasitas } \\
\text { produksi } \\
\text { Mengurangi produk out-spec }\end{array}$ & $\begin{array}{l}\text { I1: Program untuk memenuhi kebutuhan supply } \\
\text { bahan baku untuk menyediakan stok yang cukup } \\
\text { untuk memenuhi kebutuhan pelanggan untuk } \\
\text { bertujuan memberikan harga yang kommpetitif } \\
\text { I2: Meningkatkan kapasitas produksi dengan } \\
\text { kualitas tertinggi, keselamatan dan kesehatan } \\
\text { pekerja, serta kesadaran akan lingkungan }\end{array}$ \\
\hline
\end{tabular}




\begin{tabular}{|l|l|l|}
\hline $\begin{array}{l}\text { Pembelajaran dan } \\
\text { Pertumbuhan: } \\
\begin{array}{l}\text { L1 - Mengembangkan } \\
\text { Karyawan }\end{array}\end{array}$ & $\begin{array}{l}\text { Menjalankan program } \\
\text { pengembangan dan Pelatihan } \\
\text { Managemen (MT) untuk } \\
\text { proses kunci setiap tahun }\end{array}$ & $\begin{array}{l}\text { L1: program pengembangan untuk } \\
\text { mempersiapkan pemimpin dan mempertahankan } \\
\text { karyawan terbaik, regenerasi dan program } \\
\text { akselerasi untuk posisi kunci. }\end{array}$ \\
$\begin{array}{l}\text { Solid } \\
\begin{array}{l}\text { L3 - Membangun Tim } \\
\text { Sistem Terintegrasi }\end{array}\end{array}$ & $\begin{array}{l}\text { Ketersediaan posisi kunci } \\
\text { Ketersediaan kader } \\
\text { Menghubungkan komunikasi perusahaan }\end{array}$ & $\begin{array}{l}\text { L2: Mempersiapkan dan mempertahankan } \\
\text { winning team }\end{array}$ \\
& $\begin{array}{l}\text { L3: Sistem terintegrasi untuk komunikasi yang } \\
\text { lebih antar 2 perusahaan PT. Handsumtex dan } \\
\text { terintegrasi dengan peru sahaan yang ada di Cina, } \\
\text { sehingga pelayanan lebih cepat }\end{array}$ \\
\hline
\end{tabular}

Dari Peta Strategi, tersebut maka dibuatlah analisa Balanced Scorecard sebagai berikut:

\section{KESIMPULAN DAN SARAN}

Kesimpulan yang dapat ditarik oleh penulis dari analisis balanced scorecard, analisis yang berisi strategi mengenai 4 persepektif yaitu perspektif pelanggan, perspektif proses bisnis, perspektif pelanggan dan perspektif pembelajaran dan pertumbuhan. Lalu dari analisa yang ada PT. Handsumtex, telah dibentuk strateginya yang terangkum dalam 1 analisa yaitu Balanced Scorecard.

Penulis ingin menyarankan kepada PT. Handsumtex, agar mempertahankan kekonsistenan hasil kualitas produksi, lalu beradaptasi dengan perkembangan teknologi yang ada karena merupakan suatu peluang bagi PT. Handsumtex untuk terus berkembang. Lalu untuk bisa meningkatkan profit penjualan, sebaiknya PT. Handsumtex menambahkan jasa produksi garmen dalam produk baju casual dan jaket, untuk memenuhi semua kebutuhan pelanggan.

\section{DAFTAR PUSTAKA}

Sabrautzki,Stefan.2010. Strategies, Mission, Vision,Goals. Berlin : B.A International Management.

Rahman, Shahidur. 2013. Broken Promises of Globalization:The Case of the Bangladesh Garment Industry. Toronto:Lexington Books.

Porter, Michael.E. 2008. Competitive Strategy:Techniques for Analyzing Industries and Competitor. New York:The Free Press.

Pearce, John.A \& Robinson, Richard.B. 2015. Strategic Management: Planning for

Domestic \&Global Competition $14^{\text {th }}$ Edition. New York:McGraw-Hill Education.

Griffin, Ricky. 2008. Fundamentals of Management $5^{\text {th }}$ Ed. USA:Houghton Mifflin Company.

Mutale, Mathews. 2013. An Eye Opener for Small Medium Enterprises (SME's). USA:Xlibris Corporation.

Asefeso,Ade. 2013. Balanced Scorecard. United Kingdom:AA Global Sourcing Ltd.

Niven, R. Paul. 2010. Balanced Scorecard Step by Step: Maximizing Performance and Maintaining Results $2^{\text {nd }}$ Edition. Canada:John Wiley\&Sons,inc.

Kaplan,S Robert \& David P. Norton. 2015. Balanced Scorecard Success: The Kaplan-Norton Collection. Boston:Harvard Business School Press.

Blythe, Jim. 2014. Principles \&Practice of Marketing $3^{\text {rd }}$ Edition. USA:SAGE. 
